\title{
Studies on neotropical Protoneuridae. 11. Two new species of Forcepsioneura Lencioni (Odonata-Zygoptera) with a key to males of the genus
}

\author{
Angelo B.M. Machado ${ }^{1}$
}

\begin{abstract}
Forcepsioneura haerteli sp. $\mathbf{n}$. and $F$. westfalli $\mathbf{s p} . \mathbf{n}$. are described and illustrated from material collected respectively in the Santa Catarina State (Blumenau), Brazil and in the Napo Province (Limoncocha), Ecuador. Some notes are made on Forcepsioneura sancta (Hagen, 1860) and a male topotype is illustrated. A key to males of Forcepsioneura is provided.

KEY WORDS. Odonata, Protoneuridae, Forcepsioneura, new species, Brazil, Ecuador
\end{abstract}

The genus Forcepsioneura Lencioni, 1999 contains five species: F. ephippigera (Selys, 1886); F. garrisoni Lencioni, 1999; F. itatiaiae (Santos, 1970); F. lucia Machado, 2000 and $F$. sancta (Hagen, 1860). These species have been divided into two groups (MACHADO 2000), the ephippigera and the sancta groups, based on the color of the rear of the head and the degree of development of the postero-lateral prothoracic tubercles. Besides the nominal species, the ephippigera group contains an undescribed species from Ecuador, referred to by MACHADO (2000), that is now described as $F$. westfalli $\mathbf{s p}$. $\mathbf{n}$. The sancta group contains the remaining four species to which we add now $F$. haerteli sp. $\mathbf{n}$. from the State of Santa Catarina, Brazil. The species of Forcepsioneura are pin-thin damselflies that inhabit shady forests where they are very difficult to be detected. It is, therefore, probable that many new species remain to be discovered.

\section{Forcepsioneura haerteli sp. $\mathbf{n}$.}

Figs 1-5

Male. Head: labium yellowish. Labrum shining black bordered with yellow anteriorly. Anteclypeus, postclypeus and anterior part of frons shining black. Genae greenish yellow. Base of mandible brownish bellow, yellowish above. Upper part of head dark with slight metallic green and copper shining. Rear of the head pale yellow. Prothorax: laterally reddish brown; dorsally black. Posterior lobe distinctly narrower than the median one, with the margin convex (Fig. 5). Postero-lateral corner of the median lobe with a well-developed tubercle (Fig. 5). Pterothorax: mesepisternum with a metallic green stripe occupying its medial half, the lateral half reddish brown. Dorsal carina metallic copper; mesepimeron and posterior part

1) Departamento de Zoologia, Instituto de Ciências Biológicas, Universidade Federal de Minas Gerais. Caixa Postal 486, 31270-901 Belo Horizonte, Minas Gerais, Brasil. 
of metepisternum reddish brown with a narrow metallic green tapering stripe at the upper $1 / 3$ of the mesepimeron. Anterior part of metepisternum and pectus yellowish. Legs yellow except for the dorsal part of the femurae and tibiae which is brown. Claws with well-developed tooth. Wings hyaline. Pterostigma brown, surrounded by a yellow line, occupying one cell, its costal side slightly smaller than the radial one. Venation: postnodals in fore wings $13(100 \%)$; in hind wings $11(100 \%)$. R3 in fore wings originating at the 6 th $(100 \%)$ postnodal; in hind wings at the 4 th $(50 \%)$, slightly proximal to the 4 th $(25 \%)$ or 5 th $(25.0 \%)$ postnodal. IR2 in fore wings originating at the level of the 8 th $(75 \%)$, or 9 th $(25 \%)$ postnodal; in hind wings at the level of the 7 th $(50.0 \%)$ or 8 th $(50 \%)$ postnodal. CUP in fore wings terminating at one third (25\%) or half $(75 \%)$ the distance between the crossvein descending from the subnodus and that descending from the first postnodal; in hind wings terminating at half $(50.0 \%)$, or two thirds $(50.0 \%)$ of this distance. Arculus distinctly distal to the 2 nd antenodal in both wings (100\%). CuA in fore wings situated in the middle $(25.0 \%)$ of the distance between the 1 st and 2 nd antenodal or slightly beyond $(75 \%)$; in hind wing slightly beyond $(100,0 \%)$. IR3 in fore wings arising at the subnodus $(75,0 \%)$ or slightly distal to it $(25,0 \%)$; in hind wings, at the subnodus $(100,0 \%)$. IR3 in fore wings distinctly separated from R $4+$ R 5 by a small crossvein $(50,0 \%)$ or fused with it (50,0\%); in hind wings distinctly separated $(100 \%)$. First antenodal costal space much longer than the second and about as long as the third. Abdomen: segments 1-10 metallic green dorsally, darker on 6-10 with yellowish areas laterally on 1-2, ventrally on 1-6. A basal yellowish green ring at segments 3-6. A whitish pruinescent transverse stripe at the distal half of segment 9. Distal border of 10 with a very slight excavation (Fig. 3). Superior anal appendages black with white pruinescence posteriorly and on the ventro-medial process, twice longer than segment 10, directed upwards (Fig. 1), in dorsal view (Fig. 3) slightly dilated basally, slender and forcipated. Each appendage bears at its base a long and slender ventral branch (Fig. 1) that reaches to the level of the ventral part of segment 10. Occupying the basal third of each appendage there is a thorn-like triangular process (Figs 2-3), with a minute black tip, not visible in lateral view (Fig. 1) directed ventrally and medially (ventro-medial process). Inferior appendages absent. Penis with a well-developed internal fold, terminal segment with two long filaments.

Measurements (mm). Abdomen with appendages 34.1-36.6 (mean 35.3). Appendages 0.7. Length of fore wings 22.1-22.5 (mean 22.3); of hind wings 20.5-22.2 (mean 21.3). Maximum width of fore and hind wings 3.4-3.6 (mean 3.5). Pterostigma 0.6. Length of the antenodal costal spaces in fore wings 2.3-2.4 (mean 2.35), 1.7-1.8 (mean 1.75), 2.4-2.5 (mean 2.45); in hind wing 2.4, 1.6-1.7 (mean 1.65), 2.4.

Female. Unknown.

Material studied. BRAZIL, Santa Catarina: Blumenau, area of Atlantic Forest between the Monte Verde and Pastor Oswaldo Hess streets. Male holotype and 1 male paratype, 2-I-2001, A.B.M. Machado., E.R. Machado \& P.A.R. Machado legs. Holotype deposited in the A.B.M. Machado collection in Belo Horizonte, paratype deposited in the collection of the Department of Zoology, Federal University of Minas Gerais, Belo Horizonte. 

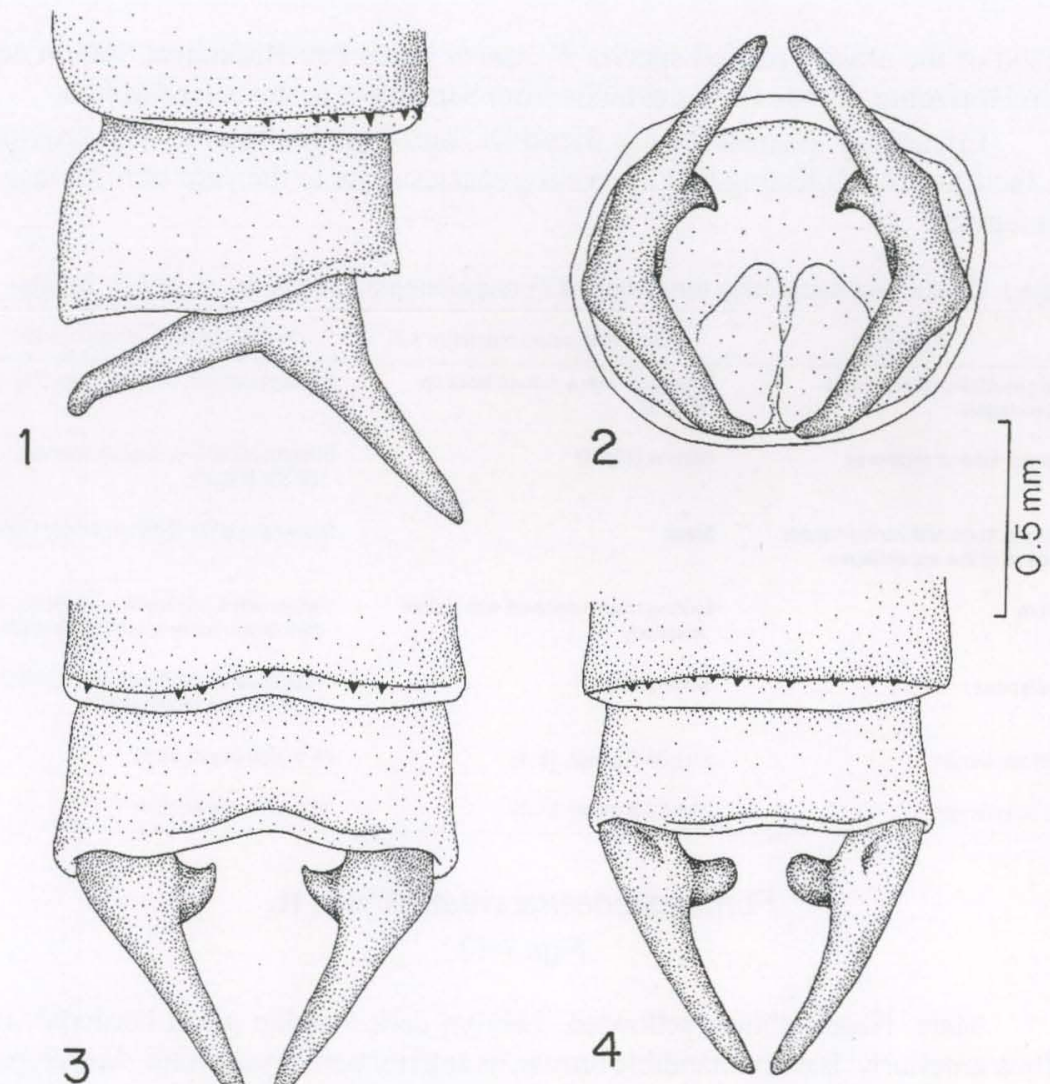

Figs 1-4. Anal appendages: Forcepsioneura haerteli sp. n. male holotype; lateral view (1), posterior view (2), dorsal view (3). F. sancta, male topotype; dorsal view (4).

Remarks. By the presence of a well-developed postero-lateral tubercle on the median lobe of the prothorax and by having the rear of the head pale, $F$. haerteli belongs to the sancta group as defined by MACHADO (2000). In the key to males of Forcepsioneura presented in this paper it keys out to couplet 5 , being closer to $F$. sancta, a species recently shown by MACHADO (1999) to be conspecific with $F$. ciganae (Santos) Since all the existing illustrations of this species are based on specimens from Rio de Janeiro and São Paulo (SANTOS 1968; LENCIONI 1999) now its prothorax (Fig. 6) and appendages (Fig. 4) are illustrated based on a male topotype from Lagoa Santa, Minas Gerais. The main differences between $F$. haerteli and $F$. sancta are shown in table I.

Forcepsioneura haerteli was found hovering above the water on a sluggish and shady stream surround by the Atlantic Forest, within the city of Blumenau. Two other specimens were seen at the occasion (January 2, 2001). When visiting the same stream in April 6, no specimen could be seen which probably indicates that the flying season of the species had ended. It is worth mentioning that the flying 
season of the closely related species $F$. sancta in the Peti Biological Station near Belo Horizonte, Minas Gerais extends from September to the end of March.

Etymology. Named for my friend Dr. Luiz Arnoldo Haertel who provided the facilities for collecting this interesting species close to the yard of his house in Blumenau.

Table I. Characters separating the males of Forcepsioneura haerteli sp. n. and F. sancta.

\begin{tabular}{|c|c|c|}
\hline Character & Forcepsioneura haerteli $(\mathrm{n}=2)$ & Forcepsioneura sancta $(n=25)$ \\
\hline $\begin{array}{l}\text { Ventro-medial process of the } \\
\text { appendages }\end{array}$ & $\begin{array}{l}\text { Triangular with a minute black tip } \\
\text { (Fig. 3) }\end{array}$ & Rectangular with rounded apex (Fig. 4) \\
\hline Posterior lobe of prothorax & Convex (Fig. 5) & $\begin{array}{l}\text { Straight (47.6\%) or slightly concave } \\
(52.3 \% \text { (Fig. 6) }\end{array}$ \\
\hline $\begin{array}{l}\text { Ventral branch and ventro-medial } \\
\text { process of the appendages }\end{array}$ & Black & Brownish yellow $(80 \%)$ or brown $(20 \%)$ \\
\hline Labrum & $\begin{array}{l}\text { Shining black bordered with yellow } \\
\text { anteriorly }\end{array}$ & $\begin{array}{l}\text { Yellow with a mid black point }(80 \%) \text {, or } \\
\text { dark brown bordered with yellow }(20 \%)\end{array}$ \\
\hline Anteclypeus & Shining black & $\begin{array}{l}\text { Predominantly greenish yellow }(90 \%) \\
\text { or yellow and brown }(20 \%)\end{array}$ \\
\hline Abdomen length & $34.1-36.6($ mean 35.3$)$ & $24.5-32.0($ mean 29.5$)$ \\
\hline Hind wing length & $20.5-22.5(\operatorname{mean} 21.3)$ & $16.9-19.8$ (mean 18.5$)$ \\
\hline
\end{tabular}

\section{Forcepsioneura westfalli sp. $\mathbf{n}$.}

Figs $7-12$

Male. Head: labium yellowish. Labrum dark metallic green bordered with yellow anteriorly. Base of mandible brown, its anterior border yellowish. Anteclypeus brown. Genae brown, with their anterior parts yellowish brown. Postclypeus and frons dark metallic green. In the teneral paratype the anteclypeus and anterior part of frons are yellow, the metallic shining being confined to the upper part of frons. Rear of the head black. Prothorax: dorsally dark metallic green, laterally dark. In the teneral paratype it is uniformly pale brown. Posterior lobe (Fig. 7) slightly narrower than the median one, with the margin convex (Fig. 7). Postero-lateral corner of the median lobe with a poorly-developed tubercle (Fig. 7). Pterothorax: mesopleuron dark metallic green, darker on the mesepimeron and the mesinfrepisternum. Metapleuron dark brown, except for the upper half of the metepimeron and a small spot on the upper part of the metinfrepisternum which are yellow. The dark brown metepimeral area is ventrally confluent with that of the opposite side behind the hind trochanters. In the teneral paratype the mesopleuron is pale brown and the metapleuron yellow with a narrow brownish stripe along the 2nd lateral suture. Legs yellow except for the tarsi which are brownish and for a brown band on the posterior parts of the femorae and the fore tibiae. Claws with a well-developed tooth. Wings hyaline. Pterostigma brown, surrounded by a yellow line, occupying one cell, its costal side slightly smaller than the radial one, the inner side oblique and the outer side convex. Venation: postnodals in fore wings $14(37.5 \%), 15(62.5 \%)$; in hind wings $11(12.5 \%), 12(37.5 \%), 13$ $(37.5 \%), 14(12.5 \%)$. R3 in fore wings originating at the 6 th $(100 \%)$ postnodal; in hind 

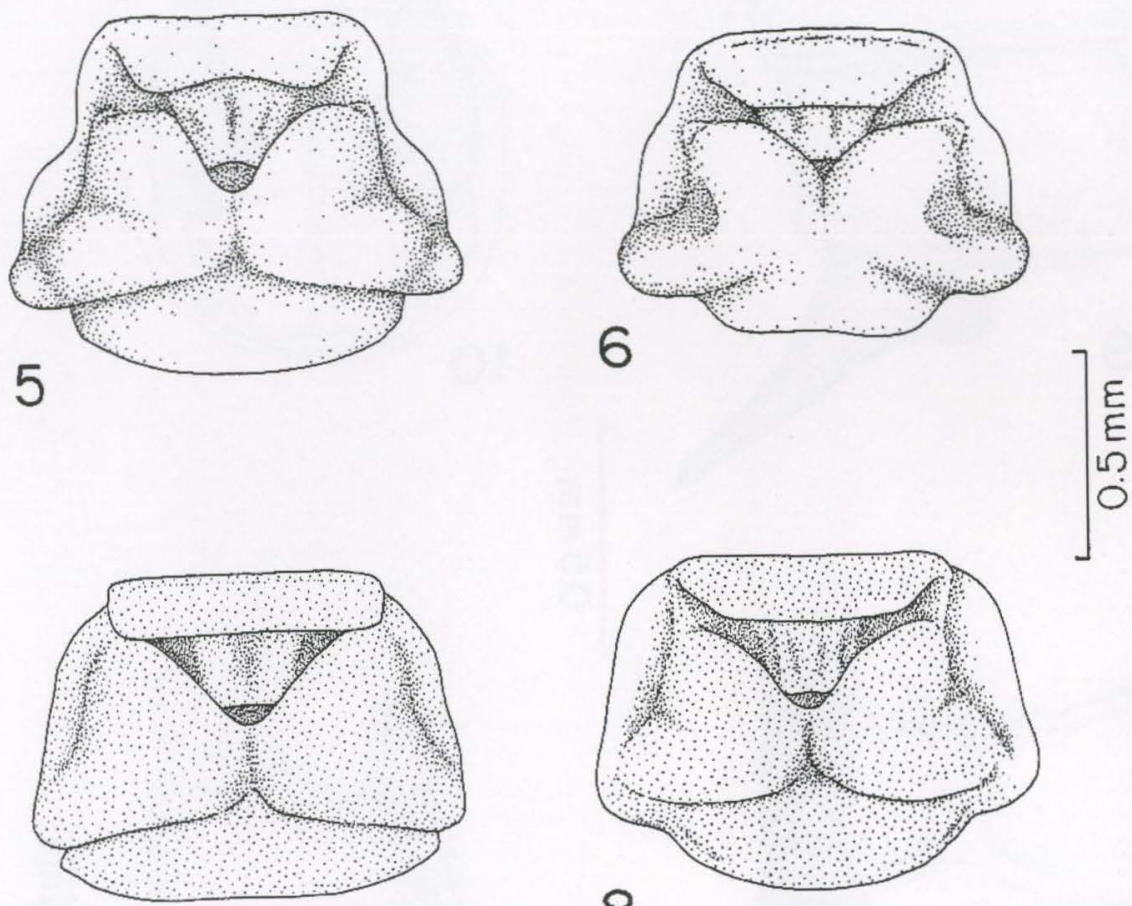

7

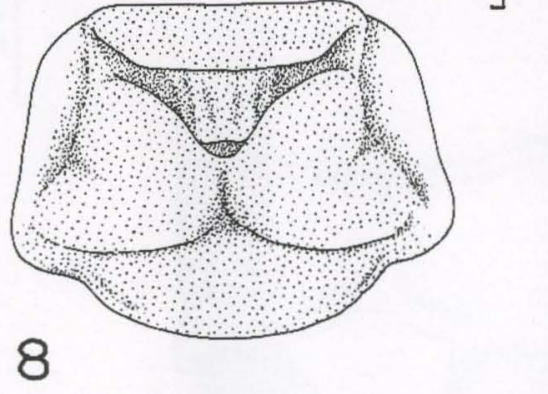

Figs 5-8. Prothorax in dorsal view: Forcepsioneura haerteli sp. n. male holotype (5); F. sancta, male topotype (6); F. westfalli sp. n. male holotype (7), female allotype (8).

wings at the 4th (100\%) postnodal. IR2 in fore wings originating at the level of the 8 th $(75 \%)$ or 9 th $(25 \%)$ posnodal; in hind wings at the level of the 7 th $(87.5 \%)$ or 8 th $(12.5 \%)$ postnodal. CUP in fore wings terminating at one third of the distance between the crossvein descending from the subnodus and that descending from the first postnodal $(100 \%)$; in hind wings terminating at one fourth $(11.1 \%)$, one third $(44.4 \%)$ or half $(44.4 \%)$ of this distance. Arculus in fore wings coinciding $(50 \%)$ or slightly distal $(50 \%)$ to the second antenodal; in hind wings coinciding $(33.3 \%)$ or slightly distal to it $(66.7 \%)$. CuA in fore wings situated in the middle of the distance between the first and second antenodal $(12.5 \%)$, or slightly beyond $87.5 \%$ ); in hind wings in the middle $(22.2 \%)$ or slightly beyond $(77.8 \%)$. IR3 in fore wings arising at the subnodus (55.5\%) or slightly distal to it (44.4\%); in hind wings at the subnodus $(77.8 \%)$ or slightly distal to it $(22.2 \%)$. IR3 in fore wings separated from R4+5 by a small $(55.5 \%)$ or very small $(44.4 \%)$ crossvein; in hind wings fused with it $(11.1 \%)$ or separated by a small $(55.6 \%)$ or very small $(33.3 \%)$ crossvein. First antenodal costal space slightly longer than the second and much longer than the third. Abdomen: 

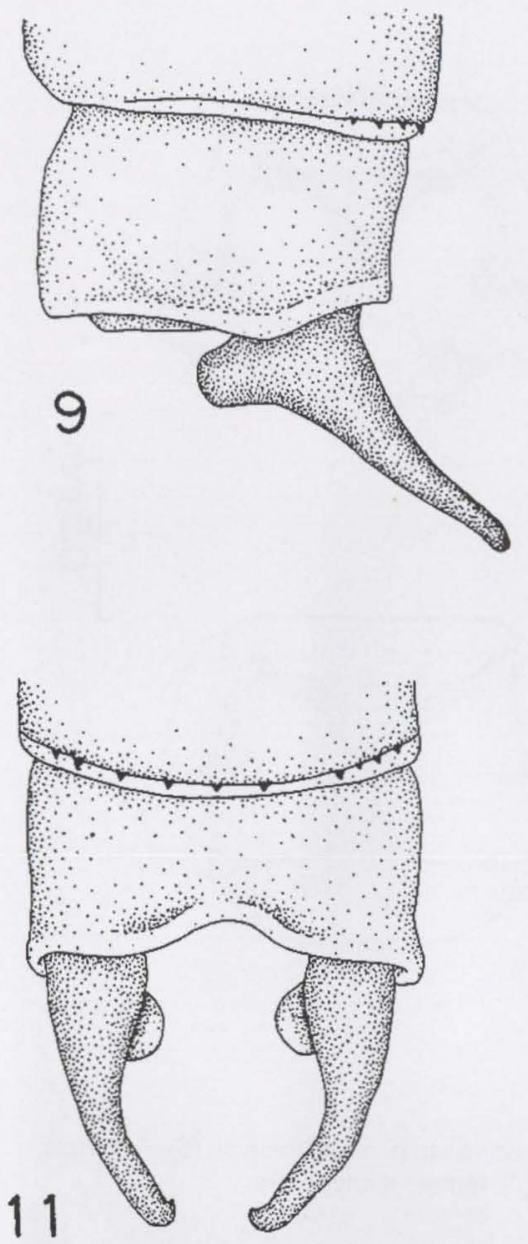

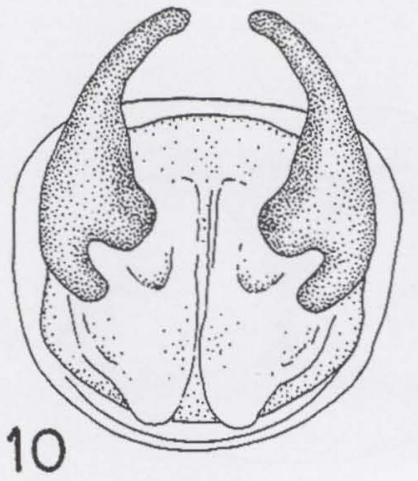

$\int \begin{aligned} & E \\ & \varepsilon \\ & 0 \\ & 0\end{aligned}$

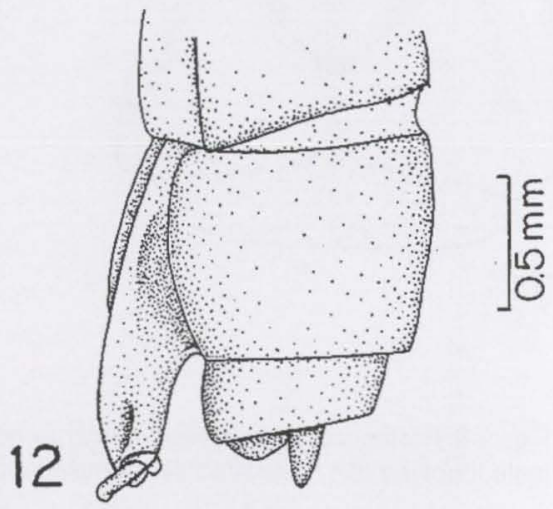

Figs 9-12. Forcepsioneura westfalli sp. n. male holotype, anal appendages: lateral view (9), posterior view (10), dorsal view (11); female allotype: ovipositor and styli (12).

segment 1 yellow with a metallic green dorsal area on its distal half. Segment 2 dark metallic green with a lateral yellow spot. Segments 3-7 and 10 dark brown dorsally. Distal $5^{\text {th }}$ of 7 and 8 metallic green dorsally. Segment 9 with whitish pruinescence. Segment 3-7 with a basal and a subapical yellow spot. Segments 1-9 yellowish ventrally, 10 dark brown. Distal border of 10 with a slight excavation (Fig. 11). Superior anal appendages black, except for the dorsal part of the ventro-medial process which is yellow, slightly longer than segment 10 , very slender and directed upward (Fig. 9), in dorsal view (Fig. 11) strongly forcipated. Each appendage bears at its base a short and stout ventral branch (Fig. 9-10). Ventro-medial process of the superior appendage situated at its basal half, in dorsal view rounded with smooth rim (Fig. 11), not visible in lateral view (Fig. 9). Inferior appendages absent. Penis with a well-de- 
veloped internal fold, terminal segment with two long filaments. In the teneral paratype the abdomen has no metallic green areas, no pruinescence on 9 and the appendages are yellow becoming brownish yellow toward the apex.

Measurements (mm). Abdomen with appendages 34.0-35.0 (mean 34.4). Appendages 0.5-0.6 (mean 0.58). Length of fore wings 22.7-24.0 (mean 23.3); of hind wings 21.0-22.7 (mean 21.7). Maximum width of fore wings 3.9-4.2 (mean 4.07), of hind wings 3.9-4.1 (mean 4.03). Pterostigma 0.6. Length of the antenodal costal spaces in fore wings 2.15-2.35 (mean 2.22), 1.90-2.20 (mean 2.05), 1.70-1.90 (mean 1.75); in hind wings 2.2-2.4 (mean 2.25), 1.9-2.1 (mean 2.02), 1.7-1.9 (mean 1.78).

Female. Head: differs from that of the male by having the labrum, genae, base of mandibles, anteclypeus and anterior part of frons yellow. The labrum has a mid posterior point black. Prothorax: dorsally dark, laterally brown with a comma shaped brownish stripe at the postero-lateral part of the median lobe. Posterior lobe as in figure 8. Tubercle at the postero-lateral corner of the median lobe virtually absent (Fig. 8). Pterothorax: mesopleuron as in the male. Metapleuron yellow except for a narrow dark band on the posterior part of the metepisternum. No ventrally confluent metepimeral dark brown area as in the male. Legs and wings as in the male. Venation: varying within the range described for the males except for: CUP in fore wings terminating at one fourth $(100 \%)$ of the distance between the crossvein descending from the subnodus and that descending from the first postnodal; IR3 in fore and hind wings coinciding with R4+5 $(75 \%)$ or separated from it by a very small crossvein $(25 \%)$. In fore and hind wings the first antenodal costal space slightly longer than the second and third $(75 \%)$ or equal to them $(25 \%)$. Abdomen: color pattern as in the male, except that the metallic green areas are black and there is no pruinescence on segment 9 . Appendages black. Ovipositor and styli black. Styli short (Fig. 12). In one of the specimens traces of dried mud were found attached to the ovipositor, the 8th sternite and the latero-ventral parts of segments 9-10.

Measurements (mm). Abdomen 33.2-35.3. Appendages 0.2. Styli 0.18-0.20. Length of the fore wings 23.6-24.0; of hind wings 21.1-22.6. Maximum width of fore and hind wings 4.0. Pterostigma 0.6. Length of antenodal costal spaces in fore wings 2.2-2.3 (mean 2.25), 2.0, 2.0-2.1 (mean 2.05); in hind wings 2.1-2.2 (mean 2.15), $1.9-2.2$ (mean 2.10); 2.1-2.2 (mean 2.10).

Material studied. ECUADOR, Napo: Limoncocha on Rio Napo, 300m: holotype male and 2 male paratypes, 15-XI-1980, M.J. Westfall, Jr. leg.; allotype female, 1 female and 2 male paratypes, 23-VIII-1980, 28-VIII-1980 (edge of ravine on hunting trail), each female with a male in the same envelope written M.F.,S.W. Dunkle leg. Total: 5 males and 2 females. Holotype, allotype and 3 paratypes deposited in the Florida State Collection of Arthropods, Gainesville, Florida; one male and one female paratypes in the A.B.M. Machado collection in Belo Horizonte.

Remarks. By having the rear of the head black and the postero-lateral tubercle of the medium prothoracic lobe poorly-developed $F$. westfalli belongs to the group ephippigera (MACHADO 2000) being very close to this species. The main difference 
between them is on the ventro-medial process of the superior appendages which has been described and illustrated by MACHADO (1985) for the lectotype of $F$. ephippigera. Differently from this species, in $F$. westfalli this process is not visible in lateral view. In dorsal view it is a rounded structure with smooth rim whereas in ephippigera it is triangular with two minute teeth. Besides, the lectotype of $F$. ephippigera has a larger abdomen $(37 \mathrm{~mm})$ than that of westfalli $(34-35 \mathrm{~mm})$. SELYS (1886) reports the presence of another specimen with smaller abdomen $(35 \mathrm{~mm})$ which we examined (MACHADO 1985) and tentatively paralectotyped as $F$. epipphigera. However it might well be another species as for an unquestionable identification one needed the appendages that were lacking. The pattern of distribution of the pruinescent areas in the adult males might also be different in the two species. In the four adult males paratypes of $F$. westfalli there is a distinct pruinescent area on abdominal segment 9 and no pruinescence on the thorax. On the other hand, the thorax of the lectotype of $F$. ephippigera has a strong pruinescence which lacks on abdominal segment 9 .

Under the name $F$. ephippigera LENCIONI (1999) presented illustrations of the appendages of a Peruvian species of Forcepsioneura which, however, does not conform to the descriptions and illustrations of this species made by MACHADO (1985) based on the lectotype. In spite of the fact that LENCIONI (1999) did not describe this species his illustrations show that it is actually $F$. westfalli, whose geographical distribution is thus considerably expanded.

There is few ecological information about the species of Forcepsioneura belonging to the ephippigera group. In eastern Ecuador and Peru DAIGLE (2000) reports $F$. ephippigera flying with Metaleptobasis maufrayi Daigle, 2000 and Psaironeura tenuissima (Selys, 1886) close to the surface near or over quiet pools in shaded rainforest swamps and sluggish streams. A note in an envelope containing one male and one female of $F$. westfalli states that they were collected at the edge of a ravine on a hunting trail. The finding of mud attached to the ovipositor and the terminal abdominal segments of a female indicates that it lays their eggs in muddy substrates within the forest, perhaps in a manner similar to Gynacantha bifida Rambur, 1842 whose females frequently have mud attached to their terminal abdominal segments (BEDÉ et. al. 2000).

Etymology. Named for my friend, Professor Dr. Minter Westfall, Jr., who collected part of the specimens of the type series and in appreciation of his important contribution to Odonatology.

\section{Key to the males of Forcepsioneura}

Since the females of three species of Forcepsioneura remain unknown, including that of the type species of the genus $F$. garrisoni, the present key refers only to males. It is considerably different from that of LENCIONI (1999), slightly modified from that of MACHADO (2000) and allows a clear distinction between the two species groups that the genus contains. Since the color of the rear of the head of $F$. garrisoni was not described it is placed in the sancta group based only on its well-developed postero-lateral prothoracic tubercles. 
1. Median prothoracic lobe with well-developed postero-lateral tubercles (Figs 5-6). Rear of the head pale. Distribution: Atlantic Forest (sancta species group) .

- Median prothoracic lobe with poorly-developed postero-lateral tubercles (Fig. 7). Rear of the head black. Distribution: Western Amazonian Forest (ephippi-

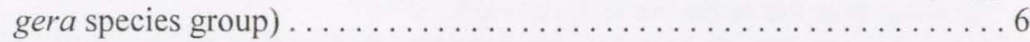

2. Ventral branch of the superior appendages short, not reaching to the level of the ventral part of segment $10 \ldots \ldots \ldots \ldots \ldots \ldots \ldots \ldots \ldots \ldots \ldots \ldots$

- Ventral branch of the superior appendages long, reaching to the level of the ventral part of segment 10 or nearly so (Fig. 1) .................. 3

3. Ventro-medial process of the superior appendages visible in lateral view .... 4 - Ventro-medial process of the superior appendages not visible in lateral view (Fig.

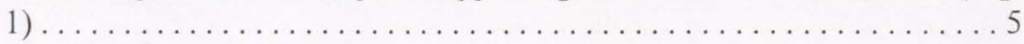

4. Posterior lobe of prothorax with a central concavity. Inferior appendages absent F. garrisoni

- Posterior lobe of prothorax convex. Inferior appendages present ....F. itatiaiae

5. Ventro-medial process of the superior appendages, in dorsal view, rectangular with the apex rounded (Fig. 4). Posterior lobe of prothorax (Fig. 6) straight or slightly concave ........................... sancta

- Ventro-medial process of the superior appendages, in dorsal view, triangular with a minute black tip (Fig. 3). Posterior lobe of prothorax convex (Fig. 5) .... F. haerteli

6. Ventro-medial process of the superior appendages not visible in lateral view (Fig. 9). In dorsal view rounded with smooth rim (Fig. 11) .......F. westfalli

- Ventro-medial process of the superior appendages visible in lateral view. In dorsal view triangular with two minute teeth ..............F. ephippigera

ACKNOWLEDGEMENTS. I am grateful to Professor Dr. Minter Westfall, Jr. from the International Odonata Research Institute, Gainesville, USA, for allowing me to study the specimens collected at Limoncocha. I am also grateful to Myrian Morato Duarte for the drawings of this paper and to Dr. Luiz A. Haertel and his wife Dr. Lucia M. Haertel for receiving me in their house in Blumenau.

\section{REFERENCES}

BedÊ, L.C.; W. Piper; G. Peters \& A.B.M. MACHAdo. 2000. Phenology and oviposition behaviour of Gynacantha bifida Rambur in Brazil (Anisoptera: Aeshnidae). Odonatologica 20 (4): 317-324.

Daigle, J.J. 2000. Metaleptobasis mauffrayi spec. nov. from Ecuador and Peru (Zygoptera: Coenagrionidae). Odonatologica 29 (4): 325-328.

Lencioni, F.A.A. 1999. The genus Phasmoneura, with description of Forcepsioneura. gen.nov. and two new species (Zygoptera: Protoneuridae). Odonatologica 28 (2): 127-137.

Machado, A.B.M. 1985. Studies on neotropical Protoneuridae. 5. Redescription of the types of Phasmoneura ephippigera (Selys 1886) (Zygoptera). Odonatologica 14 (4): 363-368. 
1999. Studies on neotropical Protoneuridae. 9. Phasmoneura ciganae Santos, conspecific with Phasmoneura sancta (Hagen) comb. n. (Zygoptera). Notul. Odonatol. 5 (3): 37-38.

2000. Studies on neotropical protoneuridae.10. Forcepsioneura lucia sp. n. from the Parque Estadual Rola Moça, Minas Gerais, Brazil. (Odonata, Zygoptera). Bol. Mus. Biol. Mello Leitão, n. ser., Santa Teresa, 11/12: 127-134.

SANToS, N.D. 1968. Phasmoneura ciganae sp. n. e notas sobre outras espécies (Odonata: Protoneuridae). Atas Soc. Biol. Rio de Janeiro 11 (6): 221-226.

SELyS-LongChamps, M.E. DE. 1886. Revision du synopsis des Agrionines.Première partie. Les légions Pseudostigma -Podagrion -Platycnemis et Protonevra. Mem. cour. Acad. r. Belg. 38: 1-233.

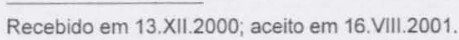

